\title{
Randomized Phase II Study of SOX+B-mab Versus SOX+C-mab in Patients With Previously Untreated Recurrent Advanced Colorectal Cancer With Wild- Type KRAS (MCSG0-1107 Study)
}

\section{Yujiro Nishizawa}

Osaka General Medical Center https://orcid.org/0000-0002-9636-4882

Naotsugu Haraguchi

Osaka International Cancer Institute: Osaka Kokusai Gan Center

Hirotoshi Kim

Rinku General Medical Center

Yoshihito Ide

Japan Community Healthcare Organization Osaka Hospital

Ken Nakata

Sakai City Medical Center: Sakai Shiritsu Sogo Iryo Center

Shu Okamura

Suita Municipal Hospital

Toshihiro Kudo

Osaka International Cancer Institute: Osaka Kokusai Gan Center

\section{Taroh Satoh}

Osaka University School of Medicine Graduate School of Medicine: Osaka Daigaku Daigakuin Igakukei Kenkyuka Igakubu

\section{Mamoru Uemura}

Osaka University School of Medicine Graduate School of Medicine: Osaka Daigaku Daigakuin Igakukei Kenkyuka Igakubu

Chu Matsuda

Osaka International Cancer Institute: Osaka Kokusai Gan Center

Tsunekazu Mizushima ( $\nabla$ tmizushima@gesurg.med.osaka-u.ac.jp )

Graduate School of Medicine, Osaka University https://orcid.org/0000-0002-0825-6823

\section{Kohei Murata}

Kansai Rosai Hospital: Kansai Rosai Byoin

\section{Yuichiro Doki}

Osaka University School of Medicine Graduate School of Medicine: Osaka Daigaku Daigakuin Igakukei Kenkyuka Igakubu

Hidetoshi Eguchi 
Osaka University School of Medicine Graduate School of Medicine: Osaka Daigaku Daigakuin Igakukei Kenkyuka Igakubu

\section{Research article}

Keywords: Cetuximab, Chemotherapy, Colorectal cancer, Early tumor shrinkage, KRAS, Oxaliplatin

Posted Date: May 25th, 2021

DOl: https://doi.org/10.21203/rs.3.rs-554716/v1

License: (a) (i) This work is licensed under a Creative Commons Attribution 4.0 International License. Read Full License 


\section{Abstract}

Background: Although chemotherapy for metastatic colorectal cancer (mCRC) has improved, the standard chemotherapy regimens for patients with RAS wild-type mCRC remain debated.

Methods: This randomized phase II, open-label, multicenter study compared the efficacy and safety of S-1 and oxaliplatin (SOX)+bevacizumab (B-mab) with SOX+cetuximab (C-mab) in patients with previously untreated recurrent advanced CRC with wild-type KRAS. Between February 2012 and October 2016, 45 patients were enrolled.

Results: Overall response rates were $59.1 \%$ and $43.5 \%(p=0.29)$ and disease control rates were $90.9 \%$ and 91.3\% ( $p=0.96)$ in the SOX+B-mab and SOX+C-mab groups, respectively. Median overall survival (OS) was 25.3 and 15.5 months $(H R=0.607, p=0.167)$ and median progression-free survival (PFS) were 11.7 and 5.5 months $(H R=0.558, p=0.077)$ in the $S O X+B-m a b$ and $S O X+C-m a b$ groups, respectively. The OS and PFS of patients with early tumor shrinkage (ETS) were not significantly different in the SOX+B-mab group. However, they were significantly better when ETS was $\geq 20$ in the $S O X+C$-mab group $(p=0.032$ and $\mathrm{p}=0.003$, respectively).

Conclusions: The efficacy and safety of SOX+B-mab and SOX+C-mab for wild-type KRAS recurrent advanced CRC as first-line chemotherapy were almost the same. Consideration of the treatment strategy based on ETS may improve patient prognosis, especially in patients receiving the SOX+C-mab regimen.

Trial registration: UMIN Clinical Trials Registry (UMIN000006706)

Date of registration: NOV/11/2011

URL of trial registry record:

https://upload.umin.ac.jp/cgi-open-bin/ctr_e/ctr_view.cgi?recptno=R000007920

\section{Background}

Colorectal cancer (CRC) is the third most common malignancy in men and the second most common in women, and it ranks third in terms of incidence but second in terms of mortality in both sexes worldwide. In 2018, over 1.8 million new CRC cases and about 900000 deaths were estimated to occur, accounting for about $10 \%$ of all cancer cases and deaths ${ }^{1}$. Approximately $20-25 \%$ of patients with CRC show synchronous metastases, and an additional $20-25 \%$ of patients will develop metastases after curative resection ${ }^{2,3}$. Although clinical outcomes in patients with metastatic colorectal cancer (mCRC) have improved over the last decade in particular and the median overall survival (OS) for patients with $\mathrm{mCRC}$ is over 30 months and more than double that of 20 years ago, the standard-of-care chemotherapy regimens for patients with RAS wild-type $\mathrm{mCRC}$ remain debated ${ }^{4}$. A phase III trial of irinotecan/5-FU/leucovorin (FOLFIRI) or oxaliplatin/5-FU/leucovorin (mFOLFOX6) with bevacizumab or cetuximab for patients with KRAS wild-type untreated mCRC (CALGB/SWOG80405), in which the primary endpoint was OS, showed 
no significant difference in the combination of chemotherapy with cetuximab or bevacizumab, but it showed a trend toward longer OS in cetuximab-treated patients versus bevacizumab-treated patients with FOLFOX ${ }^{5}$. A randomized, open-label, phase III trial of FOLFIRI plus cetuximab versus FOLFIRI plus bevacizumab as first-line treatment for patients with mCRC (FIRE-3) did not meet its primary endpoint: objective tumor response. Although there was no significant difference in progression-free survival (PFS), a difference in OS with a benefit of 3.7 months in cetuximab-treated patients was observed in the KRAS exon 2 wild-type population ${ }^{6}$. A post-hoc analysis of tumor dynamics in the final RAS wild-type subgroup showed a 7.5-month benefit in OS with cetuximab (hazard ratio [HR] 0.7) ${ }^{7}$.

S-1 is an oral anticancer agent that combines tegafur with two modulators: gimeracil and oteracil potassium $^{8}$. A phase III trial designed to validate the non-inferiority of S-1 and oxaliplatin (SOX) plus bevacizumab to mFOLFOX6 plus bevacizumab (SOFT study) in terms of PFS in patients with mCRC who had not previously received chemotherapy demonstrated the non-inferiority of SOX plus bevacizumab to mFOLFOX6 plus bevacizumab ${ }^{9}$. Updated OS analyses of the SOFT study demonstrated that SOX plus bevacizumab is non-inferior to mFOLFOX6 plus bevacizumab in terms of PFS, and the authors concluded that SOX plus bevacizumab is considered an effective regimen for first-line chemotherapy in patients with $\mathrm{mCRC}$ and can be used instead of mFOLFOX6 plus bevacizumab ${ }^{10}$.

No study has compared the difference of SOX plus bevacizumab and SOX plus cetuximab as a first-line treatment for untreated $\mathrm{mCRC}$ in the RAS-wild population. The present randomized phase II study aimed to compare SOX plus bevacizumab with SOX plus cetuximab in patients with previously untreated recurrent advanced CRC with wild-type KRAS.

\section{Methods}

\section{Ethics statements}

This Multi-center Clinical Study Group of Osaka, Colorectal Cancer Treatment Group (MCSGO)-1107 (UMIN000006706) study was conducted in accordance with the ethical principles of the Declaration of Helsinki and in compliance with Japanese ethical guidelines for clinical studies. The study protocol was approved by the institutional review board of each participating institution, and written informed consent was obtained from all patients before enrolment.

\section{Study design and patients}

This phase II, randomized, open-label, multicenter study evaluated the efficacy and safety of SOX with bevacizumab or cetuximab in patients with previously untreated, unresectable, locally advanced, or metastatic CRC with wild-type KRAS. The KRAS status of exon 2 (codons 12/13) was verified by local polymerase chain reaction. Eligible patients were aged $\geq 20$ years with previously untreated, locally advanced, histologically proven, unresectable or metastatic CRC. If postoperative adjuvant chemotherapy was administered, registration was approved as long as at least 180 days had passed since the last dose. 
In addition, patients had an Eastern Cooperative Oncology Group performance status of 0 or $1, \geq 1$ measurable lesion per RECIST version 1.1 (v1.1), life expectancy $>3$ months, and adequate organ function. Patients were excluded if they had prior adjuvant chemotherapy including oxaliplatin, active malignancy requiring treatment, active autoimmune disease, active infection requiring systemic treatment, continuous systemic steroid treatment, interstitial lung disease, active hepatitis B virus infection, active non-infectious pneumonitis, or pregnancy.

Participants were randomly assigned in a 1:1 ratio to receive either bevacizumab or cetuximab by using a validated computer system (Meditrix Corporation, Tokyo, Japan). Randomization was performed centrally with the use of the minimization method and the following stratification factors: postoperative adjuvant chemotherapy, liver metastasis, and institution. Independent central investigators used a web-based system for enrolment, which then automatically assigned patients to each cohort.

\section{Procedures}

All enrolled patients received intravenous oxaliplatin $\left(130 \mathrm{mg} / \mathrm{m}^{2}\right)$ with $7.5 \mathrm{mg} / \mathrm{kg}$ of bevacizumab (cohort A) on day 1 or intravenous oxaliplatin $\left(130 \mathrm{mg} / \mathrm{m}^{2}\right)$ with $400 \mathrm{mg} / \mathrm{m}^{2}\left(250 \mathrm{mg} / \mathrm{m}^{2}\right.$ after two courses) of cetuximab (cohort B) and TS-1 orally at a dose of $80-120 \mathrm{mg} /$ day (body surface area [BSA] $<1.25 \mathrm{~m}^{2}, 80 \mathrm{mg}$; BSA $1.25-1.50 \mathrm{~m}^{2}, 100 \mathrm{mg}$; BSA $\geq 1.50 \mathrm{~m}^{2}, 120 \mathrm{mg}$ ) that was divided into two daily doses for 14 days followed by 7 days of rest until disease progression, unacceptable toxicity, or study withdrawal. Patients who discontinued treatment for reasons other than progression were followed until loss to follow-up or withdrawal of consent. Tumor response was assessed every 9 weeks per RECIST v1. $1^{11}$. Survival was assessed every 9 weeks during follow-up. Adverse events (AEs) were graded by investigators according to the National Cancer Institute CTCAE (version 4) and were monitored throughout the study.

\section{Outcomes}

The primary end point was the overall response rate (ORR; the proportion of patients with complete response [CR] or partial response [PR]) assessed per RECIST v1.1. Secondary end points were disease control rate (DCR; the proportion of patients with $C R+P R+$ stable disease for $\geq 24$ weeks before progressive disease [PD]), OS (time from first study treatment to death as a result of any cause), PFS (time from first study treatment to first confirmed PD or death, whichever occurred first), time-to-treatment failure (TTF), treatment completion rate, rate of RO resection induction, timing of therapeutic effect, safety, and tolerability. Patients without confirmed death at the data cutoff were censored at the date of the last follow-up.

\section{Statistical analyses}

The additional response rate of the combination of bevacizumab or cetuximab to SOX therapy was assumed to be about $30 \%$. The threshold response rate in each cohort was set at $50 \%$, and the expected response rate was set at $80 \%$, with $\alpha=0.05$ (one-sided) and $1-\beta=0.9$. The required number of cases was 
calculated to be 21 cases. The target sample size was set at 25 in each cohort, with a total sample size of 50 , considering some exclusions and dropouts. A chi-square test was provided for the response rate and DCR (per RECIST v1.1) in both cohorts. Kaplan-Meier estimates were provided for PFS and OS. HRs and their confidence interval (Cls) were calculated using a Cox proportional hazards model. Early tumor shrinkage (ETS) was defined as a $\geq 20 \%$ decrease in the sum of the longest diameters of RECIST target lesions at 3 months as compared with the baseline. The depth of response (DpR) was defined as the percentage of tumor shrinkage, based on the longest diameters as compared with the baseline. The efficacy and safety analysis populations included all patients in both cohorts. Safety was assessed using descriptive analyses. Statistical analyses were performed using JMP Pro 14.1.0 software (SAS Institute, Cary, NC, USA).

\section{Results}

\section{Patients}

Between February 27, 2012, and October 31, 2016, a total of 50 patients with advanced mCRC from 11 institutions belonging to the MCSGO were enrolled in this study. Figure 1 shows a flow chart of study patients. Among the 50 patients, 3 violated the protocol and 2 withdrew consent; therefore, 45 patients were eligible for study inclusion. Table 1 summarizes the patient and tumor characteristics. These characteristics were well balanced between the two groups. In both groups, approximately $80 \%$ of tumors were located in the left side of the colon. 
Table 1

Patient and tumor characteristics treated with SOX + B-mab or SOX + C-mab

\begin{tabular}{|c|c|c|c|}
\hline Characteristics & $\begin{array}{l}\text { soX + B-mab } \\
(n=22)\end{array}$ & $\begin{array}{l}\text { soX + C-mab } \\
(n=23)\end{array}$ & $\begin{array}{l}\text { Total } \\
(n=45)\end{array}$ \\
\hline Age, median (range), year & $67(49-79)$ & $66(40-79)$ & $66(40-79)$ \\
\hline \multicolumn{4}{|l|}{ Gender } \\
\hline Male & $14(66.7)$ & $15(65.2)$ & $29(64.4)$ \\
\hline Female & $8(33.3)$ & $8(34.8)$ & $16(35.6)$ \\
\hline \multicolumn{4}{|l|}{ ECOG performance status } \\
\hline 0 & $17(71.4)$ & $18(78.3)$ & $35(77.8)$ \\
\hline 1 & $4(23.8)$ & $4(17.4)$ & $8(17.8)$ \\
\hline 2 & $1(4.8)$ & $1(4.3)$ & $2(4.4)$ \\
\hline \multicolumn{4}{|c|}{ Primary tumor resected at study entry } \\
\hline Yes & $17(77.3)$ & $14(60.9)$ & $31(68.9)$ \\
\hline No & $5(22.7)$ & $9(39.1)$ & $14(31.1)$ \\
\hline \multicolumn{4}{|c|}{ Metastatic sites at start of treatment } \\
\hline Liver only & $5(22.7)$ & $4(17.4)$ & $9(20.0)$ \\
\hline Liver & $14(63.6)$ & $15(65.2)$ & $29(64.4)$ \\
\hline Lung & $4(18.2)$ & $8(34.8)$ & $12(26.7)$ \\
\hline Lymph nodes & $15(68.2)$ & $15(65.2)$ & $30(66.7)$ \\
\hline Peritoneum & $3(13.6)$ & $5(21.7)$ & $8(17.8)$ \\
\hline Others & $1(4.5)$ & $3(13.0)$ & $4(8.9)$ \\
\hline \multicolumn{4}{|c|}{ Colorectal cancer location at diagnosis } \\
\hline Left & $17(77.3)$ & $19(82.6)$ & $36(81.4)$ \\
\hline Right & $5(21.7)$ & $4(17.4)$ & $9(18.6)$ \\
\hline
\end{tabular}

\section{Efficacy}

Median observation periods were 19.9 months (range, 1.5-55.4 months) for patients in the SOX + B-mab group and 12.0 months (range, 0.8-59.4 months) for patients in the SOX + C-mab group. The median 
number of treatment courses was five in both groups $(p=0.837$; Supplementary Table 1$)$. As shown in Table 2, the ORR for the SOX + B-mab group was $59.1 \%$, whereas that for the SOX + C-mab group was $43.5 \%(p=0.29)$. In both groups, no patient had CR. The DCR for the SOX + B-mab group was $90.9 \%$, whereas that of the SOX $+C$-mab group was $91.3 \%(p=0.96)$. Conversion surgery (equal to R0 resection induction) was performed in $18.2 \%$ of patients in the SOX + B-mab group and $4.3 \%$ of patients in the SOX $+C$-mab group ( $p=0.19$ ). TTFs were 4.61 months (range, $0.95-14.3$ months) in the SOX + B-mab group and 4.38 months (range, $0.53-12.5$ months) in the SOX $+C$-mab group $(p=0.785$; Supplementary Table 1).

Table 2

Best overall response to treatment in the SOX + B-mab and SOX + C-mab population

\begin{tabular}{|llll|}
\hline Outcomes (RECIST v1.1) & $\begin{array}{l}\text { SOX+B-mab } \\
(\mathbf{n = 2 2})\end{array}$ & $\begin{array}{l}\text { SOX+C-mab } \\
\mathbf{( n = 2 3 )}\end{array}$ & $\begin{array}{l}\text { Total } \\
\mathbf{( n = 4 5 )}\end{array}$ \\
\hline Overall response rate (CR+PR) & $13(59.1 \%)$ & $10(43.5 \%)$ & $23(51.1 \%), \mathrm{P}=0.29$ \\
\hline Disease control rate (CR+PR+SD) & $20(90.9 \%)$ & $21(91.3 \%)$ & $41(91.1 \%), \mathrm{P}=0.96$ \\
\hline Complete response (CR) & $0(0.0 \%)$ & $0(0.0 \%)$ & $0(0.0 \%)$ \\
\hline Partial response (PR) & $13(59.1 \%)$ & $10(43.5 \%)$ & $23(51.1 \%)$ \\
\hline Stable disease (SD) & $7(31.8 \%)$ & $11(47.8 \%)$ & $18(40.0 \%)$ \\
\hline Progressive disease (PD) & $1(4.5 \%)$ & $1(4.3 \%)$ & $2(4.4 \%)$ \\
\hline Could not be evaluated (NE) & $1(4.5 \%)$ & $1(4.3 \%)$ & $2(4.4 \%)$ \\
\hline Conversion surgery & $4(18.2 \%)$ & $1(4.3 \%)$ & $5(11.1 \%), P=0.19$ \\
\hline
\end{tabular}

Figure 2 shows the Kaplan-Meier curves for OS and PFS for all patients or patients with only left-sided colorectal cancer. For all patients, median durations of OS were 25.3 months ( $95 \% \mathrm{Cl}$ : 16.5-39.4 months) in the SOX + B-mab group and 15.5 months ( $95 \% \mathrm{Cl}$ : 7.30-30.4 months, $\mathrm{p}=0.167)$ in the SOX + C-mab group. Median durations of PFS were 11.7 months (95\% Cl: 7.37-18.2 months) in the SOX + B-mab group and 5.5 months $(95 \% \mathrm{Cl}: 3.36-10.1$ months, $\mathrm{p}=0.077)$ in the SOX $+\mathrm{C}-\mathrm{mab}$ group. According to the Kaplan-Meier curves limited to left-sided colon cancer, OS was not significantly different between the groups $(p=0.55)$, but PFS was significantly better in the SOX + B-mab group (12.0 months [95\% Cl: 7.921.4 months]) than in the SOX + C-mab group (5.1 months [95\% Cl: 3.3-9.7. months, $p=0.019]$ ).

Next, ETS was assessed in each group, and the cutoff point of ETS was set to $20 \%$. ETS of the SOX + Bmab group was $37.5 \%$, whereas that of the SOX $+C$-mab group was $30.1 \%(p=0.42$, Supplementary Table 2). Figure 3 shows Kaplan-Meier curves for OS and PFS of the SOX + B-mab and SOX + C-mab groups classified by the presence or absence of ETS. In the SOX + B-mab group, OS and PFS were not significantly different with and without ETS. However, in the SOX + C-mab group, patients with ETS had 
significantly better OS (30.4 months [95\% Cl: 8.0-44.3 months, $\mathrm{p}=0.032])$ and PFS (12.0 months [95\% Cl: 5.1-19.7 months, $p=0.003])$ than those without ETS.

Additionally, the DpR of the SOX + B-mab group was $40 \%$, whereas that of the SOX + C-mab group was $30.1 \%$ ( $p=0.41$, Supplementary Table 2$)$. Supplementary Fig. 1 shows the waterfall plot of the best change in size of target lesions. Days and courses of timing of therapeutic effect were not significantly different between the two groups (Supplementary Table 3).

\section{Safety}

The treatment-related AEs are summarized in Table 3. All grades of AEs occurred in 20/22 patients (90.9\%) in the SOX + B-mab group and $23 / 23$ patients (100\%) in the SOX + C-mab group. Grade $\geq 3$ AEs occurred in $10 / 22$ patients $(45.6 \%)$ in the SOX + B-mab group and $11 / 23$ of patients (47.8\%) in the SOX+ $\mathrm{C}$-mab group. The most common AEs were peripheral sensory neuropathy in both groups, and allergic reaction and paronychia were distinctive AEs in the SOX + C-mab group. Skin and subcutaneous tissue disorders were also AEs characterized in the SOX + C-mab group. One patient in the SOX + B-mab group had grade 4 malaise, but no patients died of treatment-related AEs. AEs that caused discontinuation of treatment occurred in seven patients $(31.8 \%)$ in the SOX + B-mab group and nine patients $(39.1 \%)$ in the SOX $+C$-mab group $(p=0.61)$. 
Table 3

Adverse events (treatment-related)

\begin{tabular}{|c|c|c|c|c|}
\hline \multirow[t]{3}{*}{ Adverse events } & \multicolumn{2}{|c|}{ soX + B-mab $(n=22)$} & \multicolumn{2}{|c|}{ soX + C-mab $(n=23)$} \\
\hline & All grades & $\geqq$ Grade 3 & All grades (\%) & $\geqq$ Grade 3 \\
\hline & $(\%)$ & $(\%)$ & & (\%) \\
\hline \multicolumn{5}{|l|}{ Hematologic adverse events } \\
\hline Leucopenia & $3(13.6)$ & $0(0.0)$ & $1(4.3)$ & $0(0.0)$ \\
\hline Anemia & $7(31.8)$ & $1(4.8)$ & $6(26.1)$ & $1(4.3)$ \\
\hline Thrombocytopenia & $6(27.2)$ & $1(4.8)$ & $8(34.8)$ & $3(13.0)$ \\
\hline Hyperbilirubinemia & $8(36.4)$ & $2(9.1)$ & $4(17.4)$ & $0(0.0)$ \\
\hline Hypoalbuminemia & $6(27.2)$ & $1(4.8)$ & $7(30.4)$ & $0(0.0)$ \\
\hline Aspartate aminotransferase increased & $6(27.2)$ & $0(0.0)$ & $8(34.8)$ & $1(4.3)$ \\
\hline Alanine aminotransferase increased & $6(27.2)$ & $0(0.0)$ & $9(39.1)$ & $1(4.3)$ \\
\hline Hypomagnesemia & $1(4.8)$ & $0(0.0)$ & $1(4.3)$ & $0(0.0)$ \\
\hline Hyperkalemia & $1(4.8)$ & $0(0.0)$ & $3(13.0)$ & $0(0.0)$ \\
\hline \multicolumn{5}{|l|}{ Nonhematologic adverse events } \\
\hline Mucositis oral & $4(18.2)$ & $0(0.0)$ & $6(26.1)$ & $0(0.0)$ \\
\hline Nausea & $3(13.6)$ & $0(0.0)$ & $5(21.7)$ & $0(0.0)$ \\
\hline Vomiting & $1(4.8)$ & $0(0.0)$ & $5(21.7)$ & $1(4.3)$ \\
\hline Diarrhea & $5(22.7)$ & $1(4.8)$ & $11(43.5)$ & $2(8.7)$ \\
\hline Anorexia & $9(40.9)$ & $2(9.1)$ & $9(39.1)$ & $2(8.7)$ \\
\hline Fatigue & $3(13.6)$ & $2(9.1)$ & $5(21.7)$ & $0(0.0)$ \\
\hline Malaise & $7(31.8)$ & $1(4.8)$ & $9(39.1)$ & $0(0.0)$ \\
\hline Allergic reaction & $0(0.0)$ & $0(0.0)$ & $2(8.7)$ & $0(0.0)$ \\
\hline Peripheral sensory neuropathy & $18(81.8)$ & $2(9.1)$ & $16(69.6)$ & $0(0.0)$ \\
\hline Peripheral motor neuropathy & $3(13.6)$ & $0(0.0)$ & $2(8.7)$ & $0(0.0)$ \\
\hline Palmar-plantar erythrodysesthesia syndrome & $2(9.1)$ & $0(0.0)$ & $4(17.4)$ & $0(0.0)$ \\
\hline Proteinuria & $3(13.6)$ & $0(0.0)$ & $3(13.0)$ & $0(0.0)$ \\
\hline Hypertension & $3(13.6)$ & $0(0.0)$ & $2(8.7)$ & $1(4.3)$ \\
\hline Skin and subcutaneous tissue disorders & $1(4.8)$ & $0(0.0)$ & $12(52.2)$ & $0(0.0)$ \\
\hline
\end{tabular}




\begin{tabular}{|lllll|}
\hline Adverse events & \multicolumn{2}{l|}{ SOX + B-mab $(\mathbf{n = 2 2})$} & \multicolumn{2}{l|}{ SOX + C-mab $(\mathbf{n}=23)$} \\
\hline Paronychia & $0(0.0)$ & $0(0.0)$ & $10(43.5)$ & $0(0.0)$ \\
\hline Total & $20(90.9)$ & $10(45.6)$ & $23(100)$ & $11(47.8)$ \\
\hline
\end{tabular}

\section{Discussion}

This is the first randomized phase II, open-label, multicenter study to compared the efficacy and safety of SOX + bevacizumab with SOX + cetuximab in patients with previously untreated recurrent advanced colorectal cancer with wild-type KRAS. The ORR, the primary endpoint, was not significantly different between the two study groups $(p=0.29)$. However, the treatment effect tended to be better in the SOX $+B$ mab group than in the SOX $+\mathrm{C}$-mab group. Although there was no significant difference between the two groups in PFS and OS, these outcomes tended to be better in the SOX + B-mab group than in the SOX + Cmab group; there were differences of about 10 months for OS and about 6 months for PFS in both groups. The SOFT study reported a PFS of 11.7 months and an ORR of $61.5 \%$ in the SOX + B-mab group ${ }^{10}$, which were similar to the results in the SOX + B-mab group of our study (PFS, 11.7 months; ORR, $59.1 \%$ ). Additionally, in our study, there was no difference in the number of treatment courses, TTF, and rate of discontinuation due to side effects between the groups.

Because the SOX + B-mab and SOX + C-mab groups comprised about $80 \%$ of left-sided colon cancer in our study, we analyzed OS and PFS in only patients with left-sided colorectal cancer. Although OS was not different between the groups, PFS was significantly better in the SOX + B-mab group than in the SOX + C-mab group. In general, the significance of anti-epidermal growth factor receptor (EGFR) antibodies has been proven in wild-type RAS left-sided colorectal cancer ${ }^{12}$. The ESMO guidelines recommend the use of anti-EGFR antibodies as a treatment for wild-type RAS left-sided colon cancer ${ }^{13}$. In the FIRE-3 study, although there was no significant difference in PFS, there was a difference in OS with a benefit of 3.7 months in the C-mab-treated patients in the wild-type KRAS exon 2 population compared to B-mabtreated patients ${ }^{7}$. There are possibilities behind the differences in PFS in the SOX + C-mab and SOX + Bmab groups in patients with left-sided colorectal cancer. The first possibility is secondary or subsequent treatment after failure of this study regimen. In this study, we did not limit secondary or subsequent treatment. In fact, three patients (13.6\%) in the SOX + B-mab group used a regimen that included cetuximab and nine patients (39.1\%) of the SOX $+\mathrm{C}$-mab group used a regimen that included bevacizumab in secondary or subsequent treatment. The second possibility is the number of treatment courses. In the SOFT study, the median number of treatment courses was eight. However, that of our study was five in both groups. This relatively shorter treatment course may affect the difference in PFS. The third possibility is dose intensity. Although AEs seemed to not be different in hematological events, non-hematological events of peripheral neuropathy and hypertension were high in the SOX + B-mab group. Allergic reactions and paronychia were distinctive, and skin and subcutaneous tissue disorders characterized AEs in the SOX + C-mab group. Notably, all grades of AEs in nausea, vomiting, and diarrhea were observed almost over double in the SOX $+\mathrm{C}$-mab group. The combination of oral fluoropyrimidine 
with anti-EGFR agents is known to increase the risk of diarrhea ${ }^{14}$. The concomitant study of the MRC COIN trial showed that OxFU + cetuximab and OxCap + cetuximab were equivalent in terms of OS, ORR, and RRS(rate of radical surgeries). Nonetheless, PFS was longer with OxFU + cetuximab than with OxCap + cetuximab, and the authors described a possibility that the higher toxicity associated with $\geq$ grade 3 nausea, diarrhea, and palmar-plantar erythema in OxCap + cetuximab led to greater dose reductions and a lower total dose of oxaliplatin ${ }^{15}$. These AEs possibly decrease the dose intensity in the combination of SOX with cetuximab, and it is necessary to assess dose intensity in a large-scale study.

A limitation of this study is that KRAS status was assessed only on exon 2 (codons 12/13). Evidence from the PRIME study and CRYSTAL study has shown that tumors with additional RAS mutations (exons 3 and 4 of KRAS and exons 2, 3, and 4 of NRAS) other than those in KRAS exon 2 display a lack of response to EGFR-targeting monoclonal antibodies ${ }^{16,17}$. Furthermore, BRAF mutations are almost exclusively non-overlapping with $R A S$ mutations and are reported to be negative predictive biomarkers for EGFR antibody therapy in patients with $\mathrm{mCRC}^{18-20}$. Final analysis of the randomized PEAK trial supports the importance of expanded RAS mutational analysis and showed longer median PFS and median OS for panitumumab versus bevacizumab in wild-type RAS and BRAF $C R C^{21}$. In response to the results of these clinical trials, the ESMO consensus guideline recommends expanding RAS mutational analysis to at least KRAS exons 2, 3, and 4 (codons 12, 13, 59, 61, 117, and 146) and NRAS exons 2,3 , and 4 (codons 12, 13, 59,61 , and 117) alongside the assessment of tumor BRAF mutational status. The presence of these minor RAS and BRAF mutations may have affected the results of this study. Indeed, other RAS mutations were detected in $14.7 \%$ and $31 \%$ of evaluable tumors previously assessed to be wild-type KRAS exon 2 in the CRYSTAL study and in the OPUS study, respectively ${ }^{16,21}$.

Recently, ETS and DpR have been focused on as prognostic factors for RFS and OS after first-line treatment of $\mathrm{mCRC}^{6}$. In our study, OS and PFS did not significantly differ between ETS $<20$ and ETS $\geq 20$ in the SOX + B-mab group. However, OS and PFS were significantly better in the ETS $\geq 20$ group than in the ETS $<20$ group among patients in the SOX + C-mab group. Anti-EGFR antibody drugs are reported to have a shorter TTR, better DpR, and more ETS than B-mab ${ }^{21}$. Patients with ETS in both groups had an OS $>30$ months and PFS > 11 months, but the benefits of ETS to OS and PFS were significantly higher in the SOX C-mab group than in the SOX + B-mab group. The assessment of ETS can be a powerful marker for prognosis even in patients receiving SOX with $\mathrm{C}$-mab. When $\mathrm{C}$-mab is used in combination with SOX, evaluation of ETS is indispensable, and if ETS is $<20$ after 3 months, consideration of the treatment strategy including drug change may be useful for improving patient prognosis.

\section{Conclusions}

The safety and efficacy of SOX + B-mab and SOX + C-mab for wild-type KRAS, recurrent advanced CRC as a first-line chemotherapy were almost the same, but they tended to be better in the SOX + B-mab group than in the SOX + C-mab group. ETS was more correlated with PFS in the SOX + C-mab group than in the 
SOX + B-mab group, and consideration of treatment strategy based on ETS may improve patient prognosis, especially in patients receiving the $\mathrm{SOX}+\mathrm{C}$-mab regimen.

\section{Abbreviations}

mCRC: metastatic colorectal cancer

SOX: S-1 and oxaliplatin

B-mab: bevacizumab

C-mab: cetuximab

ETS: early tumour shrinkage

OS: overall survival

FOLFIRI: irinotecan/5-FU/leucovorin

FOLFOX: oxaliplatin/5-FU/leucovorin

PFS: progression-free survival

AEs: Adverse events

ORR: overall response rate

DCR: disease control rate

TTF: time to treatment failure

Cl: confidence interval

DpR: depth of response

\section{Declarations}

\section{Ethics approval and consent to participate}

This Multi-center Clinical Study Group of Osaka, Colorectal Cancer Treatment Group-1107 (UMIN000006706) study was conducted in accordance with the ethical principles of the Declaration of Helsinki and in compliance with Japanese ethical guidelines for clinical studies. The study protocol was approved by the institutional review board of each participating institution (Osaka General Medical Center, Osaka University, Rinku General Medical Center, Japan Community Healthcare Organization Osaka Hospital, Sakai City Medical Center, Suita Municipal Hospital, Hyogo Prefectural Nishinomiya 
Hospital, National Hospital Organization Osaka National Hospital, Saiseikai Tondabayashi Hospital, Osaka Rosai Hospital, Itami City Hospital). Written informed consent was obtained from all patients before enrolment.

\section{Consent for publication}

Our manuscript does not contain any individual person's data in any form.

\section{Availability of data and materials}

The datasets used and/or analyzed during the current study are available from the corresponding author on reasonable request.

\section{Competing interests}

The authors declare that they have no competing interests.

\section{Funding}

This research did not receive any specific grant from funding agencies in the public, commercial, or notfor-profit sectors.

\section{Authors' contributions}

$\mathrm{YN}, \mathrm{NH}, \mathrm{HK}, \mathrm{YI}, \mathrm{KN}, \mathrm{SO}, \mathrm{TK}$, and TS provided study materials and/or recruited patients. $\mathrm{YN}, \mathrm{NH}, \mathrm{TK}, \mathrm{TS}, \mathrm{MU}$, $\mathrm{CM}, \mathrm{TM}, \mathrm{KM}, \mathrm{YD}$, and $\mathrm{HE}$ were involved in data analysis and interpretation writing and development of the manuscript. All authors approved the final draft.

\section{Acknowledgments}

We thank all patients, their families, and the investigators involved in this study.

\section{References}

1. Bray F, Ferlay J, Soerjomataram I, Siegel RL, Torre LA, Jemal A. Global cancer statistics 2018 : GLOBOCAN estimates of incidence and mortality worldwide for 36 cancers in 185 countries. CA Cancer J Clin. 2018;68:394-424.

2. Mantke R, Schmidt U, Wolff S, Kube R, Lippert H. Incidence of synchronous liver metastases in patients with colorectal cancer in relationship to clinico-pathologic characteristics. Results of a German prospective multicentre observational study. Eur J Surg Oncol. 2012;38:259-65.

3. van der Pool AE, Damhuis RA, ljzermans JN, de Wilt JH, Eggermont AM, Kranse R, Verhoef C. Trends in incidence, treatment and survival of patients with stage IV colorectal cancer: a population-based series. Colorectal Dis. 2012;14:56-61. 
4. Van Cutsem E, Cervantes A, Adam R, Sobrero A, Van Krieken JH, Aderka D, Aranda Aguilar E, Bardelli A, Benson A, Bodoky G, Ciardiello F, D'Hoore A, Diaz-Rubio E, Douillard JY, Ducreux M, Falcone A, Grothey A, Gruenberger T, Haustermans K, Heinemann V, Hoff P, Köhne CH, Labianca R, Laurent-Puig P, Ma B, Maughan T, Muro K, Normanno N, Österlund P, Oyen WJ, Papamichael D, Pentheroudakis G, Pfeiffer P, Price TJ, Punt C, Ricke J, Roth A, Salazar R, Scheithauer W, Schmoll HJ, Tabernero J, Taïeb J, Tejpar S, Wasan H, Yoshino T, Zaanan A, Arnold D. ESMO consensus guidelines for the management of patients with metastatic colorectal cancer. Ann Oncol. 2016;27:1386-422.

5. Venook AP, Niedzwiecki D, Lenz HJ, Innocenti F, Fruth B, Meyerhardt JA, Schrag D, Greene C, O'Neil BH, Atkins JN, Berry S, Polite BN, O'Reilly EM, Goldberg RM, Hochster HS, Schilsky RL, Bertagnolli MM, El-Khoueiry AB, Watson P, Benson AB 3rd, Mulkerin DL, Mayer RJ, Blanke C. Effect of First-Line Chemotherapy Combined With Cetuximab or Bevacizumab on Overall Survival in Patients With KRAS Wild-Type Advanced or Metastatic Colorectal Cancer: A Randomized Clinical Trial. JAMA. 2017;317:2392-401.

6. Stintzing S, Modest DP, Rossius L, Lerch MM, von Weikersthal LF, Decker T, Kiani A, Vehling-Kaiser U, Al-Batran SE, Heintges T, Lerchenmüller C, Kahl C, Seipelt G, Kullmann F, Stauch M, Scheithauer W, Held S, Giessen-Jung C, Moehler M, Jagenburg A, Kirchner T, Jung A, Heinemann V, FIRE-3 investigators. FOLFIRI plus cetuximab versus FOLFIRI plus bevacizumab for metastatic colorectal cancer (FIRE-3): a post-hoc analysis of tumour dynamics in the final RAS wild-type subgroup of this randomised open-label phase 3 trial. Lancet Oncol. 2016;17:1426-34.

7. Heinemann V, von Weikersthal LF, Decker T, Kiani A, Vehling-Kaiser U, Al-Batran SE, Heintges T, Lerchenmüller C, Kahl C, Seipelt G, Kullmann F, Stauch M, Scheithauer W, Hielscher J, Scholz M, Müller S, Link H, Niederle N, Rost A, Höffkes HG, Moehler M, Lindig RU, Modest DP, Rossius L, Kirchner T, Jung A, Stintzing S. FOLFIRI plus cetuximab versus FOLFIRI plus bevacizumab as firstline treatment for patients with metastatic colorectal cancer (FIRE-3): a randomised, open-label, phase 3 trial. Lancet Oncol. 2014;15:1065-75.

8. Satoh T, Sakata Y. S-1 for the treatment of gastrointestinal cancer. Expert Opin Pharmacother. 2012;13:1943-59.

9. Yamada Y, Takahari D, Matsumoto H, Baba H, Nakamura M, Yoshida K, Yoshida M, Iwamoto S, Shimada K, Komatsu Y, Sasaki Y, Satoh T, Takahashi K, Mishima H, Muro K, Watanabe M, Sakata Y, Morita S, Shimada Y, Sugihara K. Leucovorin, fluorouracil, and oxaliplatin plus bevacizumab versus S-1 and oxaliplatin plus bevacizumab in patients with metastatic colorectal cancer (SOFT): an openlabel, non-inferiority, randomised phase 3 trial. Lancet Oncol. 2013;14:1278-86.

10. Baba H, Yamada Y, Takahari D, Matsumoto H, Yoshida K, Nakamura M, Yoshida M, Iwamoto S, Shimada K, Komatsu Y, Sasaki Y, Satoh T, Takahashi K, Mishima H, Muro K, Watanabe M, Sakata Y, Morita S, Shimada Y, Sugihara K. S-1 and oxaliplatin (SOX) plus bevacizumab versus mFOLFOX6 plus bevacizumab as first-line treatment for patients with metastatic colorectal cancer: updated overall survival analyses of the open-label, non-inferiority, randomised phase III: SOFT study. ESMO Open. 2017;2:e000135. 
11. Eisenhauer EA, Therasse P, Bogaerts J, Schwartz LH, Sargent D, Ford R, Dancey J, Arbuck S, Gwyther S, Mooney M, Rubinstein L, Shankar L, Dodd L, Kaplan R, Lacombe D, Verweij J. New response evaluation criteria in solid tumours: revised RECIST guideline (version 1.1). Euro J Cancer. 2009;45:228-47.

12. Modest DP, Stintzing S, von Weikersthal LF, Decker T, Kiani A, Vehling-Kaiser U, Al-Batran SE, Heintges T, Kahl C, Seipelt G, Kullmann F, Scheithauer W, Moehler M, Holch JW, von Einem JC, Held S, Heinemann V. Exploring the effect of primary tumor sidedness on therapeutic efficacy across treatment lines in patients with metastatic colorectal cancer: analysis of FIRE-3 (AIOKRK0306). Oncotarget. 2017;8:105749-60.

13. Yoshino T, Arnold D, Taniguchi H, Pentheroudakis G, Yamazaki K, Xu RH, Kim TW, Ismail F, Tan IB, Yeh KH, Grothey A, Zhang S, Ahn JB, Mastura MY, Chong D, Chen LT, Kopetz S, Eguchi-Nakajima T, Ebi H, Ohtsu A, Cervantes A, Muro K, Tabernero J, Minami H, Ciardiello F, Douillard JY. Pan-Asian adapted ESMO consensus guidelines for the management of patients with metastatic colorectal cancer: a JSMO-ESMO initiative endorsed by CSCO, KACO, MOS, SSO and TOS. Ann Oncol. 2018;29:44-70.

14. Tol J, Koopman M, Rodenburg CJ, Cats A, Creemers GJ, Schrama JG, Erdkamp FL, Vos AH, Mol L, Antonini NF, Punt CJ. A randomised phase III study on capecitabine, oxaliplatin and bevacizumab with or without cetuximab in first-line advanced colorectal cancer, the CAIRO2 study of the Dutch Colorectal Cancer Group (DCCG). An interim analysis of toxicity. Ann Oncol. 2008;19:734-8.

15. Madi A, Fisher D, Wilson RH, Adams RA, Meade AM, Kenny SL, Nichols LL, Seymour MT, Wasan H, Kaplan R, Maughan TS. Oxaliplatin/capecitabine vs oxaliplatin/infusional 5-FU in advanced colorectal cancer: the MRC COIN trial. Br J Cancer. 2012;107:1037-43.

16. Van Cutsem E, Lenz HJ, Köhne CH, Heinemann V, Tejpar S, Melezínek I, Beier F, Stroh C, Rougier P, van Krieken JH, Ciardiello F. Fluorouracil, leucovorin, and irinotecan plus cetuximab treatment and RAS mutations in colorectal cancer. J Clin Oncol. 2015;33:692-700.

17. Douillard JY, Oliner KS, Siena S, Tabernero J, Burkes R, Barugel M, Humblet Y, Bodoky G, Cunningham D, Jassem J, Rivera F, Kocákova I, Ruff P, Błasińska-Morawiec M, Šmakal M, Canon JL, Rother M, Williams R, Rong A, Wiezorek J, Sidhu R, Patterson SD. Panitumumab-FOLFOX4 treatment and RAS mutations in colorectal cancer. N Engl J Med. 2013;369:1023-34.

18. Rowland A, Dias MM, Wiese MD, Kichenadasse G, McKinnon RA, Karapetis CS, Sorich MJ. Metaanalysis of BRAF mutation as a predictive biomarker of benefit from anti-EGFR monoclonal antibody therapy for RAS wild-type metastatic colorectal cancer. Br J Cancer. 2015;112:1888-94.

19. Seymour MT, Brown SR, Middleton G, Maughan T, Richman S, Gwyther S, Lowe C, Seligmann JF, Wadsley J, Maisey N, Chau I, Hill M, Dawson L, Falk S, O'Callaghan A, Benstead K, Chambers P, Oliver A, Marshall H, Napp V, Quirke P. Panitumumab and irinotecan versus irinotecan alone for patients with KRAS wild-type, fluorouracil-resistant advanced colorectal cancer (PICCOLO): a prospectively stratified randomised trial. Lancet Oncol. 2013;14:749-59.

20. Peeters M, Oliner KS, Parker A, Siena S, Van Cutsem E, Huang J, Humblet Y, Van Laethem JL, André T, Wiezorek J, Reese D, Patterson SD. Massively parallel tumor multigene sequencing to evaluate 
response to panitumumab in a randomized phase III study of metastatic colorectal cancer. Clin Cancer Res. 2013;19:1902-12.

21. Rivera F, Karthaus M, Hecht JR, Sevilla I, Forget F, Fasola G, Canon JL, Guan X, Demonty G, Schwartzberg LS. Final analysis of the randomised PEAK trial: overall survival and tumour responses during first-line treatment with mFOLFOX6 plus either panitumumab or bevacizumab in patients with metastatic colorectal carcinoma. Int J Colorectal Dis. 2017;32:1179-90.

22. Bokemeyer C, Köhne CH, Ciardiello F, Lenz HJ, Heinemann V, Klinkhardt U, Beier F, Duecker K, van Krieker JH, Tejpar S. FOLFOX4 plus cetuximab treatment and RAS mutations in colorectal cancer. Eur J Cancer. 2015;51:1243-52.

\section{Figures}
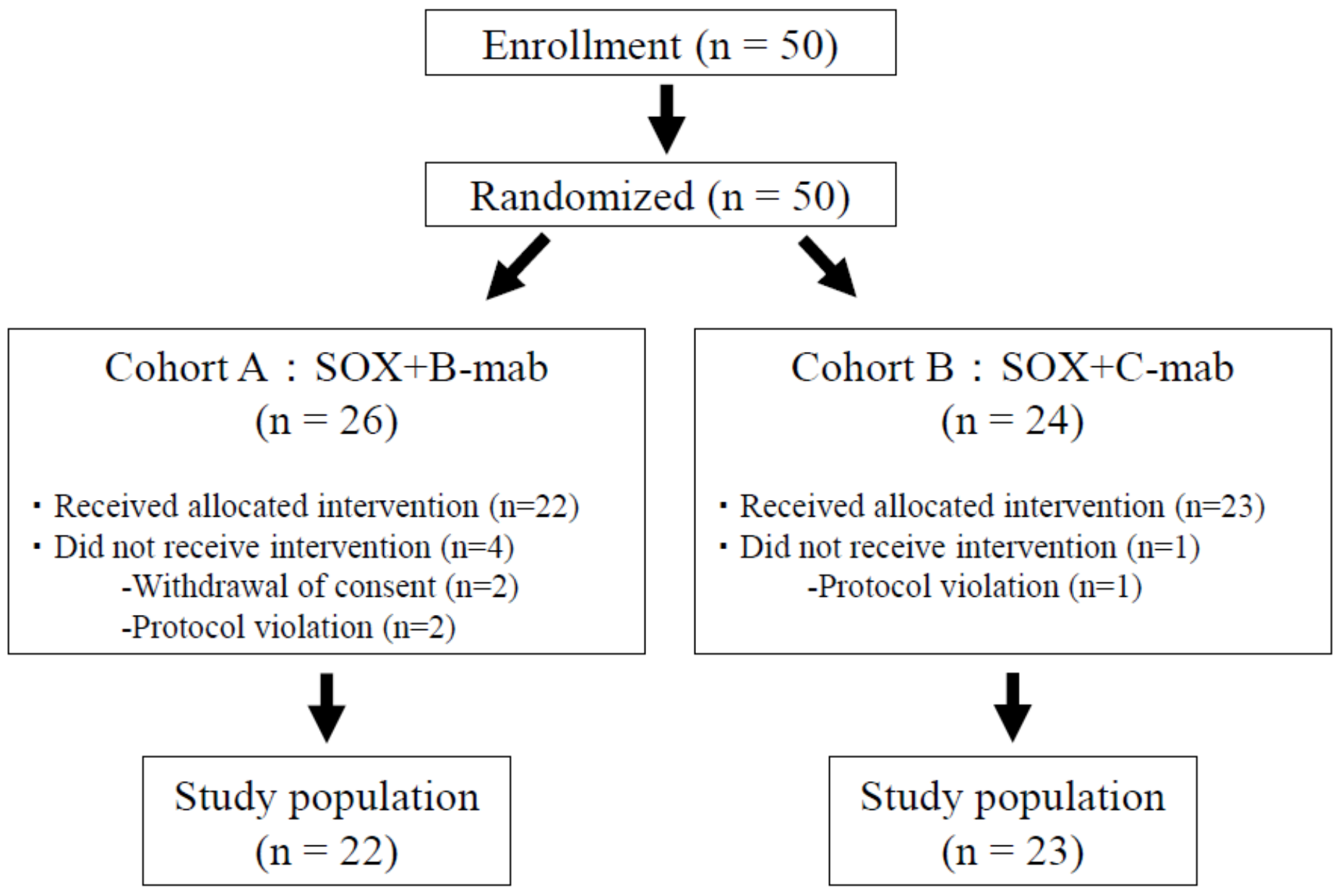

\section{Figure 1}

Flow chart. Forty-five patients were eligible for study inclusion 

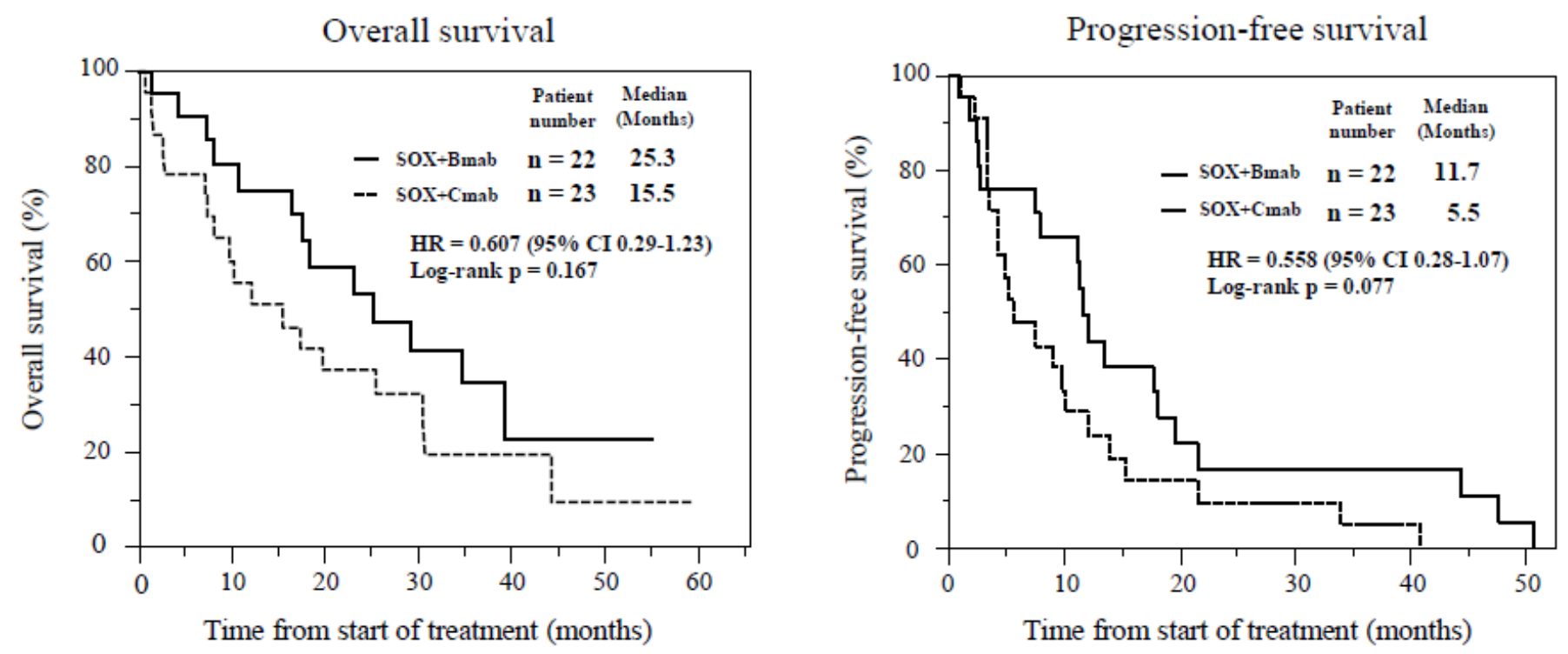

b
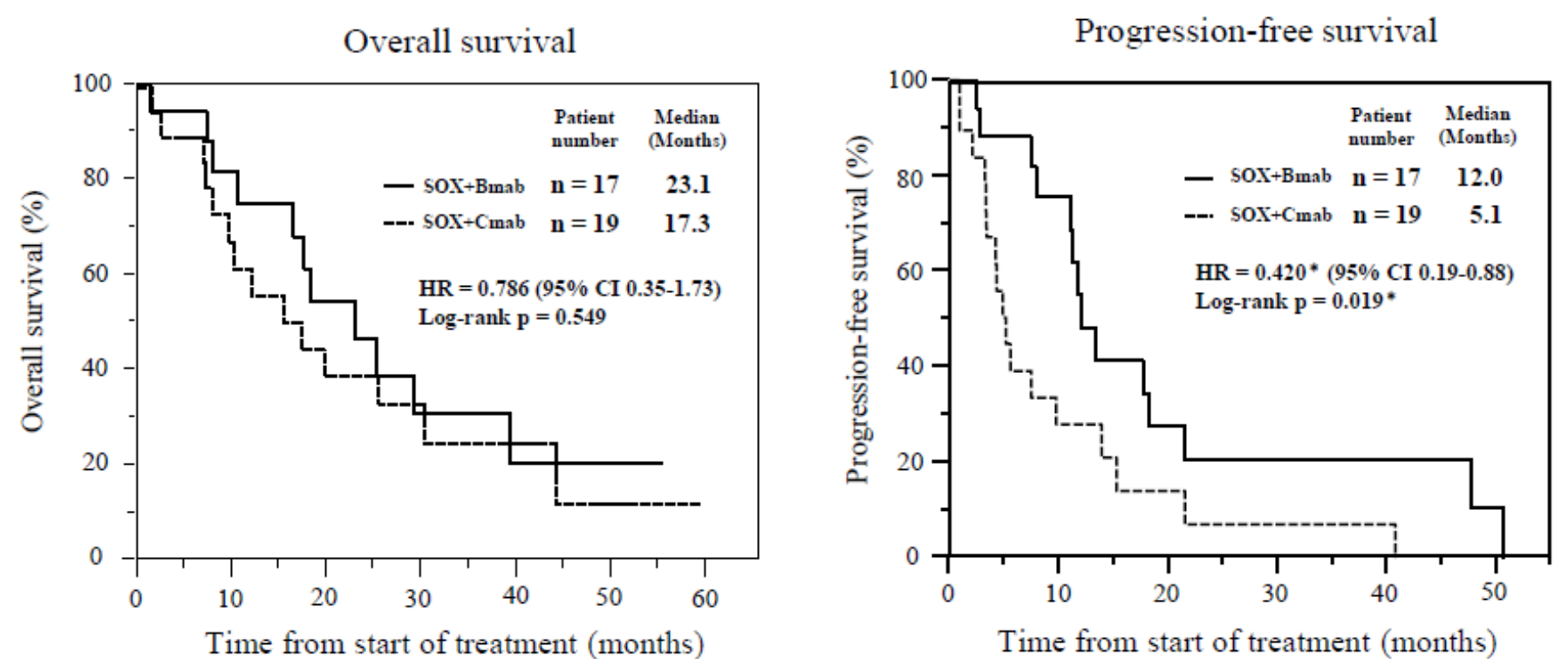

\section{Figure 2}

Kaplan-Meier curves for overall survival and progression-free survival for all patients (a) and patients with left-sided colorectal cancer (b). Solid black line: SOX+B-mab, dotted black line: SOX+C-mab. * indicates $<0.05$ 


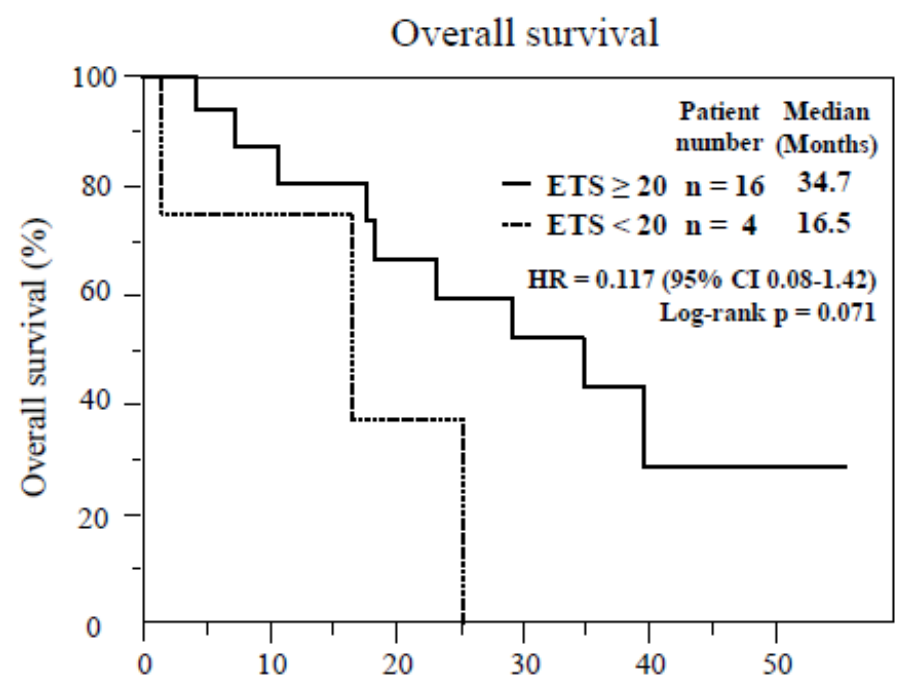

Time from start of treatment (months)

b $\quad \mathrm{sOX}+\mathrm{C}-\mathrm{mab}$

Overall survival

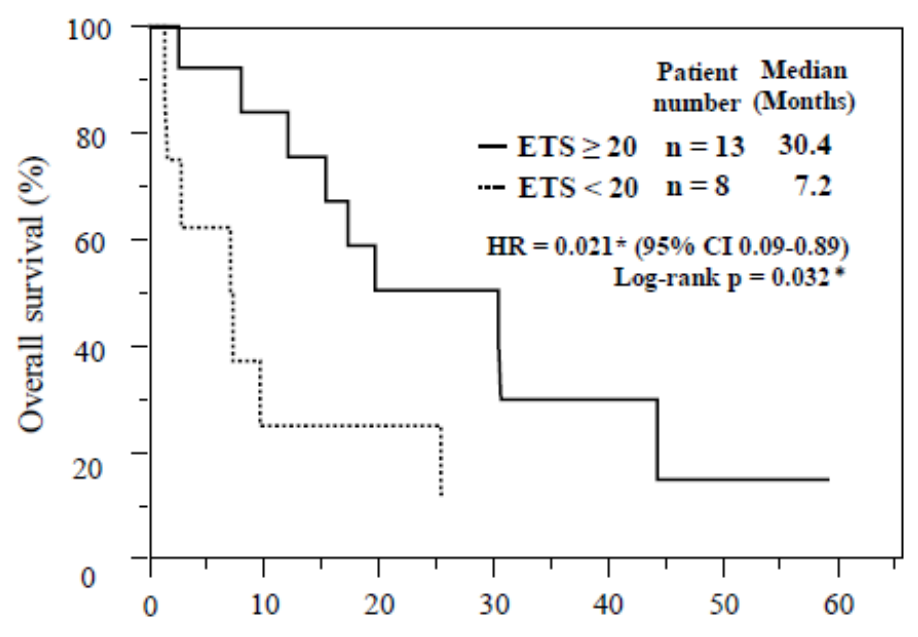

Progression-free survival

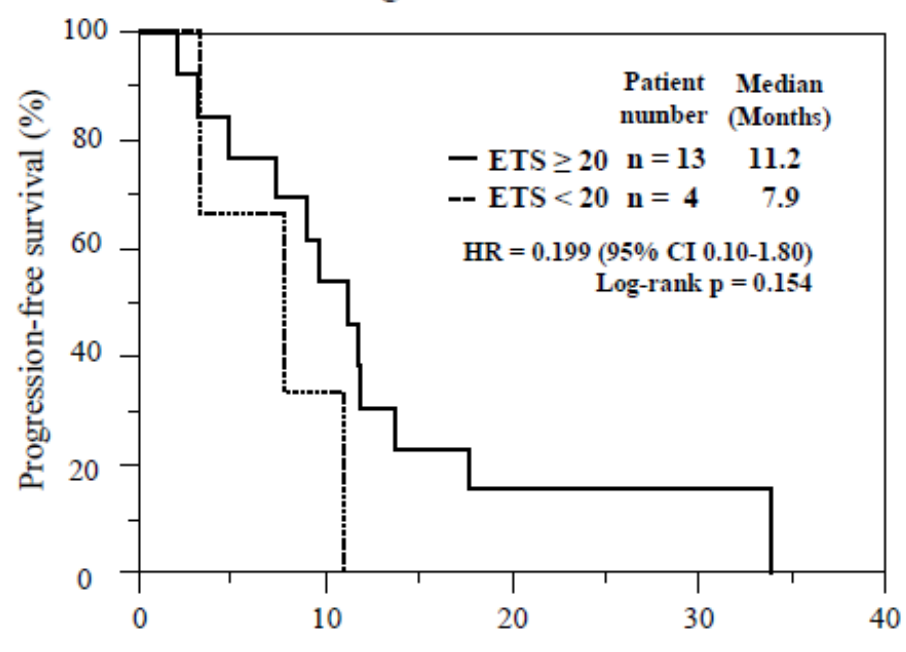

Time from start of treatment (months)

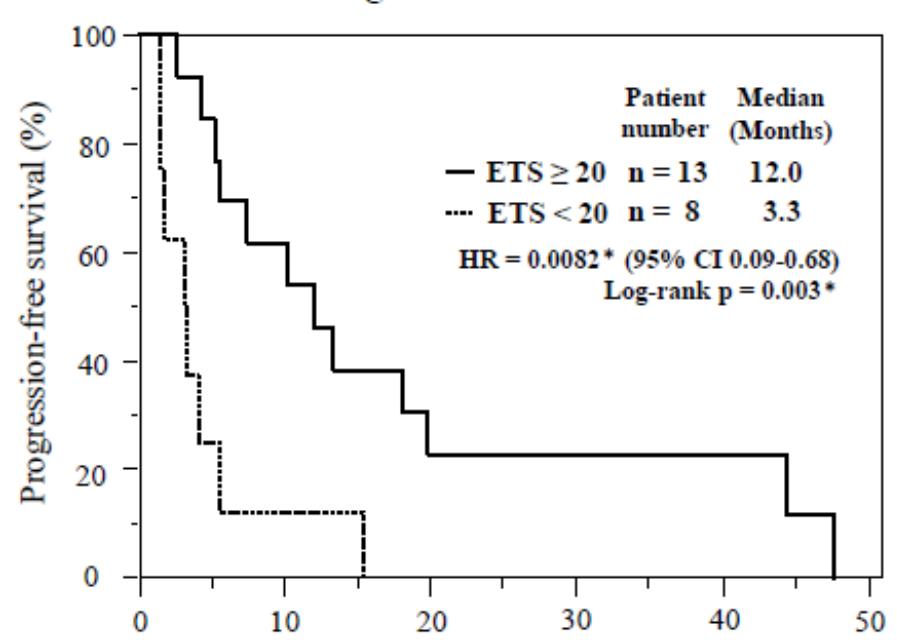

Figure 3

Kaplan-Meier curves for overall survival and progression-free survival for SOX+B-mab group (a) and SOX+C-mab group (b) classified by ETS. Solid black line: ETS $\geq 20$, dotted black line: ETS $<20$ * indicates $<0.05$

\section{Supplementary Files}

This is a list of supplementary files associated with this preprint. Click to download.

- SupplementaryFigure1.pdf 
- SupplementaryTable1.docx

- SupplementaryTable2.docx

- SupplementaryTable3.docx 